\title{
El reformismo militar de Carlos III: mito y realidad
}

\author{
Francisco Andújar Castillo
}

Recibido: 30 de junio de 2016 / Aceptado: 5 de septiembre de 2016

Resumen. En esta aportación se procede a realizar un análisis crítico de las reformas militares que impulsó Carlos III a lo largo de su reinado. Para ello, por un lado, se plantea una visión de las mismas situándolas en el contexto de toda la centuria y, por otro, se trata de dar respuesta a dos cuestiones. La primera, se centra en responder a si durante su reinado se modificó o no el sistema de recompensas en la carrera militar hasta llegar a los más altos grados del generalato, es decir, si "principios ilustrados" como los de mérito, estudio o formación científico-técnica, fueron o no los vectores que rigieron la promoción de los oficiales generales. La segunda, busca analizar si Carlos III recompensó o no a los altos mandos del ejército con la más alta distinción que otorgaba, la de noble titulado, a quienes le servían en la carrera de las armas.

Palabras clave: ejército; Carlos III; reformas militares; Oficiales Generales; nobleza.

\section{[en] The military reformism of Carlos III: Myth and Reality}

\begin{abstract}
In this contribution we proceed to make a critical analysis of the military reforms that drove Carlos III throughout his reign. To do this, on the one hand, a vision of them by placing them in the context of the entire century arises and, secondly, trying to answer two questions. The first focuses on answering whether during his reign was modified or not the reward system in the military career to reach the highest echelons of generalship, that is, if "enlightened principles" such as merit, study or training scientific and technical were or were not vectors that governed the promotion of general officers. The second seeks to analyze whether or not Carlos III rewarded the senior army with the highest distinction granted, the titled noble, who served him in the arms race.
\end{abstract}

Keywords: Army; Carlos III; Military Reforms; General Officers; Nobility.

Sumario. 1. Las recompensas sociales: la nobleza titulada. 2. La carrera en el generalato: recompensar la antigüedad. 3. La hornada de tenientes generales de 1779: venalidad y nobleza versus ciencia.

Cómo citar: Andújar Castillo, F. (2016) El reformismo militar de Carlos III: mito y realidad, en Cuadernos de Historia Moderna 41.2, 337-354. 
La argumentación que sitúa a Carlos III como monarca reformista tiene uno de sus principales puntos de anclaje en los cambios introducidos en la institución militar durante su reinado. La historiografía se ha esforzado por presentarlo como el soberano que impulsó una serie de transformaciones que cambiaron de forma radical los que hasta entonces habían sido los fundamentos del ejército borbónico. En su haber siempre se ha situado la promulgación de las nuevas Ordenanzas Militares de 1768 que tan larga vida iban a tener en el ejército español, la introducción del sistema de quintas, la creación de academias y escuelas militares y, desde luego, las reformas introducidas en el ejército de América consistentes en una considerable ampliación de la maquinaria militar, la creación de nuevos cuerpos de ejército, la generalización del sistema de milicias y el envío desde España de numerosos regimientos que debían reforzar al que tradicionalmente se ha llamado como "ejército de dotación".

Sin embargo, en nuestra opinión, esas reformas militares que convirtieron a Carlos III en paradigma del cambio en el siglo XVIII deben ser analizadas en su contexto y con perspectiva. Así, el símbolo del reformismo que fueron las Ordenanzas de 1768 debería ser estudiado más en analizando su aplicación efectiva que el mero contenido de su articulado. Las innovaciones que introdujeron en relación con las compendiadas por Felipe V en 1728, o las dictadas incluso durante los primeros años de la Guerra de Sucesión, no parece que fuesen excesivamente significativas, más allá de que, en efecto, supusieron la adopción en España del sistema militar prusiano. Un análisis comparativo evidencia que el verdadero reformismo en materia militar se produjo durante los primeros años del reinado de Felipe $\mathrm{V}$, cuando el ejército borbónico experimentó una radical transformación como consecuencia de la adopción del sistema organizativo francés. ${ }^{2}$

Por otro lado, basta señalar que justo cuando se estaban imprimiendo aquellas Ordenanzas Militares, tanto en la Secretaría del Despacho de Guerra -para engrosar una particular caja- como con ocasión de la formación de nuevos regimientos, se estaban vendiendo - "beneficiando"- empleos de oficiales que venían a conculcar unas normas que establecían que la antigüedad en el servicio y, en menor medida el mérito, debían ser los principios vertebradores de la jerarquía militar. Por entonces el "mérito del dinero" permitía ingresar directamente en los reales ejércitos con el grado de capitán sin haber desempeñado antes el empleo de teniente, e incluso se podía conseguir con caudales un grado de coronel. ${ }^{3}$ Sobre el papel -léase las Ordenanzaslos grados de la oficialidad no se podían conseguir por dinero pero, en la práctica, la misma Secretaría del Despacho de Guerra que había impulsado la publicación de las Ordenanzas las convertía en papel mojado al otorgar despachos de oficiales a cambio de la entrega de ciertas sumas de dinero.

Otra reforma atribuida a Carlos III fue la implantación de un sistema de reclutamiento regular basado en quintas. En efecto, el intento de normalizar con carácter anual las quintas fue introducido por la ordenanza de 1770 para reemplazo del ejér-

Andújar Castillo, F.: "La reforma militar en el reinado de Felipe V", en Pereira Iglesias, J. L. (coord.): Felipe V de Borbón, 1701-1746, Córdoba, Universidad de Córdoba, 2002, pp. 615-640; ANDúJAR Castillo, F.: "El ejército de Felipe V. Estrategias y problemas de una reforma", en Serrano, E. (coord.): Felipe Vy su tiempo. Congreso Internacional, Zaragoza, Institución "Fernando el Católico", 2004, pp. 655-676; RIBOT García, L. A.: "Las reformas militares y navales en tiempos de Felipe V", en MAZA, E., Marcos, C. y Serrano, R. (coords.): Estudios de historia: homenaje al profesor Jesús María Palomares, Valladolid, Universidad de Valladolid, 2006, pp. 129-162.

3 Andúuar Castillo, F.: El sonido del dinero. Monarquía, ejército y venalidad en la España del siglo XVIII, Madrid, Marcial Pons, 2004. 
cito. Sin embargo, la única novedad estribaba en ese intento de lograr cada año nutrir los ejércitos de "ciudadanos" que quedaran obligados a defender su nación, pues con anterioridad las quintas ya se habían utilizado desde el reinado de Felipe V como una de las formas de reclutamiento que coexistieron con el enganche de voluntarios y las levas de "vagamundos". 4

Por lo que respecta a la creación de Academias y Escuelas de formación militar es cierto que se produjo un notable impulso durante el reinado de Carlos III pues a ese período corresponde la fundación de centros de tanta relevancia como el Real Colegio de Artillería de Segovia, erigido en el año de 1764, y la más efímera -abierta en 1774 y cerrada en 1779- "Real Escuela Militar de Ávila", creada bajo el impulso del irlandés Alejandro O'Reilly, y que a la postre fue un intento frustrado de modernización de la enseñanza militar en España. ${ }^{5}$ Le seguirían luego otros centros menores como la Real Academia de Caballería y Picadero de Ocaña (1775-1790). No obstante, esas fundaciones no pueden eclipsar centros tan importantes y de tan larga vigencia en el ejército borbónico como fueron la Real Academia Militar de Matemáticas de Barcelona fundada en 1699, y que tras un cierre temporal durante la Guerra de Sucesión permaneció abierta hasta 1805, o la Real Academia de Orán, erigida en 1732 y cerrada en 1790, a las cuales habría que sumar la Academia Militar de Badajoz, creada en 1712, la de Pamplona fundada en 1719 o la de Ceuta instituida en $1739 .{ }^{6}$ Del mismo modo, el Seminario de Nobles de Madrid, que abrió sus puertas en el año 1725, aunque fue concebido para la formación de hijos de familias de la aristocracia, a la postre acabó funcionando como un centro de educación de futuros militares, siendo por tanto fundación de Felipe V. ${ }^{7}$ Por tanto, parece evidente que el reformismo militar en materia de formación de oficiales no puede atribuirse, como se ha venido haciendo hasta no hace mucho, al "patrimonio" de Carlos III.

Por otro lado, aunque no ha sido entendido por la historiografía como una reforma, la orientación del ejército hacia las tareas de orden público y vigilancia del contrabando, o lo que es lo mismo, la militarización del orden público, sí parece que fue uno de los cambios más importantes que se produjeron a finales del reinado de Carlos III en relación al ejército. Como ha señalado Enrique Martínez Ruiz, la floración de una serie de cuerpos de ejército especiales dedicados de forma específica al control del orden público viene a desmitificar la imagen historiográfica de época pacífica y armoniosa que tiene el siglo XVIII. ${ }^{8}$ Pero no solo se crearon compañías especiales destinadas a la seguridad pública, sino que también los cuerpos del ejército regular tuvieron una de sus principales misiones en el control del orden público y en tratar de poner coto al problema del contrabando que conoció una etapa de

Puell DE la Villa, F.: “La ordenanza del reemplazo anual de 1770”, Hispania, 189 (1995), pp. 205-228.

Recio Morales, O.: "Un intento de modernización del ejército borbónico del XVIII: la Real Escuela Militar de Ávila (1774)", Investigaciones históricas: Época moderna y contemporánea, 32 (2012), pp. 145-172.

6 García Hurtado, M. R.: "La vida en las academias militares del siglo XVIII", en García Hurtado, M. R. (coord.): Soldados de la Ilustración, A Coruña, Universidad de A Coruña, 2012, pp. 37-60.

7 AndúJar Castillo, F.: "El Seminario de Nobles de Madrid en el siglo XVIII. Un estudio social", Cuadernos de Historia Moderna, Anejo III (2004), pp. 201-225; Artola Renedo, A., Chaparro Saínz, A.: "El entorno de los alumnos del Real Seminario de Nobles de Madrid (1727-1808). Elementos para una prosopografía relacional", en Imízcoz Beunza, J. M. y Álvaro Chaparro Sáinz, A. (eds.): Educación, redes y producción de élites en el siglo XVIII, Madrid, Sílex, 2013, pp. 177-200.

8 Martínez Ruiz, E.: "Vivir la guerra, vivir la paz: los militares y el mantenimiento del orden público", en García Hurtado, M. R. (ed.): Soldados de la Ilustración: el ejército español en el siglo XVIII (ed.): A Coruña, Universidad de A Coruña, 2012, pp. 83-100. 
fuerte intensificación en el último tercio de la centuria. ${ }^{9}$ Esa militarización del orden público también se produjo en América, pues aun cuando la prioridad fue la defensa del vasto territorio costero frente a los potenciales enemigos, particularmente los ingleses, también el ejército fue el encargado de sofocar las revueltas indígenas de Tupac Amaru y Tupac Catan en los Andes, así como las que tuvieron lugar en Nueva España.

Con todo, la verdadera reforma militar del reinado de Carlos III en América, o si se prefiere, el proceso de militarización del territorio americano, se produjo desde el momento en que las unidades del ejército regular peninsular fueron enviadas de forma sistemática hacia aquellas tierras, formando parte del denominado "ejército de refuerzo" que debía completar la estructura militar allí existente y que, en teoría, tras algunos años de permanencia en ese destino ultramarino debían regresar a España. Su misión, como su nombre indica, fue reforzar determinados puntos débiles del sistema defensivo americano o bien participar en acciones concretas, de modo que el ejército se viese incrementado con cuerpos profesionales, "expertos", frente al abrumador peso que hasta entonces tenían los cuerpos de milicias en América, mucho más numerosos que el llamado "ejército de dotación" o profesional que se había formado con carácter permanente como mejor salvaguarda.

\section{Las recompensas sociales: la nobleza titulada}

Por tanto, un somero balance general sobre el reformismo militar de Carlos III permite atisbar tanto luces como sombras - como ya lo señalara Terrón Ponce- ${ }^{10}$ con un cierto predominio de estas últimas o, en propiedad, podemos afirmar que las reformas introducidas en el ejército durante el reinado de Felipe $\mathrm{V}$ fueron muy superiores a las que años más tarde acometiera su hijo, a pesar de haber pasado a la historia este último como símbolo del reformismo en materia militar. No obstante, creemos que el debate está abierto pues cierta historiografía mantiene un posicionamiento distinto al que acabamos de enunciar en las páginas precedentes. Y precisamente a contribuir a ese debate responden las reflexiones de esta aportación en torno a una interrogante que nos parece capital, pues en la práctica trata de explicar la propia efectividad del mando de las tropas. En esencia nos interrogamos acerca de si durante el reinado de Carlos III se modificó o no el sistema de recompensas en la carrera militar hasta llegar a los más altos grados del generalato. En otros términos, nos preguntamos acerca de si el mérito, el estudio o la formación científico-técnica, fueron o no los vectores que rigieron la promoción de los oficiales generales. En teoría, esos deberían haber sido los principios "ilustrados" para otorgar los ascensos en la carrera de las armas hasta llegar a los más elevados peldaños del escalafón castrense ¿Pero fue esa la realidad del ejército?

Un análisis en profundidad del problema planteado no puede considerar tan solo la carrera profesional de los oficiales generales de Carlos III sino que, como acaeció durante todo el Antiguo Régimen, debe valorar igualmente otra carrera, de no me-

Melón Jiménez, M. A.: Los tentáculos de la hidra: contrabando y militarización del orden público en España (1784-1800), Madrid, Sílex, 2009.

10 Terrón Ponce, J. L.: La casaca y la toga: luces y sombras de la reforma militar durante el reinado de Carlos III, Mahón, Institut Menorquí d'Estudis, 2010. 
nor trascendencia, como fue la de los honores, pues hay que tener en cuenta que en aquella sociedad la promoción social tenía tanta importancia como el disfrute de los rangos militares que otorgaba el ejercicio de la carrera de las armas. La movilidad social ascendente que podía proporcionar el servicio en el ejército era una meta tan importante como el salario que se percibía en cada uno de los grados del escalafón, pues en un ejército vertebrado sobre la diferenciación social que establecía la sangre plebeya o hidalga, la aspiración de cualquier militar era escalar tanto en la carrera de los honores como en la profesional. ${ }^{11}$ Lo pone de manifiesto con meridiana claridad la eterna aspiración a vestir los hábitos de las órdenes militares. ${ }^{12}$

Por ende, cabe interrogarse acerca de si Carlos III recompensó o no a los mandos de su ejército con la más preciada distinción social, la nobleza titulada, aquella que situaba en la cumbre de la pirámide social, con los títulos de marqués o conde, a quienes habían servido al rey. En primer término, un análisis cuantitativo arroja unos resultados negativos a dicha pregunta, es decir, que haber servido en la carrera de las armas no supuso un mérito principal para acceder a tan alta distinción. A lo largo del reinado de Carlos III, con ligeros matices diferenciales en las estimaciones de los cálculos según unos u otros autores, se crearon un total de 230 nuevos Títulos de Castilla, Navarra y Aragón -de marqueses, condes y duques- de los cuales 23 recayeron en militares, es decir, el 10\% del total. ${ }^{13}$ La nómina de militares titulados presenta algunos nombres conocidos y una gran mayoría de anónimos oficiales del ejército: los condes de Asalto, O’Reilly, Ofalia, Unión, Benalúa, Gálvez y Lomas; los marqueses de la Real Defensa, Sobremonte, Avilés, Monteolivar, Algorfa, Valdemoro, Loreto, Tabalosos, Guisla, Camarena, Perijáa, Cervera, Casa Henestrosa, Casa Calvo, Riocavado; y el duque de Mahón, ya titulado en Francia como duque de Crillón. ${ }^{14}$

Si relacionamos esos oficiales del ejército que fueron distinguidos con títulos nobiliarios con los grados que desempeñaban en el escalafón castrense antes de recibir esos honores, obtenemos el cuadro 1 en el que se observa que los empleos de mayor rango no fueron siempre los más remunerados con títulos nobiliarios. Además, el estudio de cada una de esas trayectorias permite constatar que en los grados inferiores de esa jerarquía no hubo méritos militares singulares de ningún tipo como para ser distinguidos con marquesados y condados.

11 AndúJar CAStillo, F.: "Milicia, venalidad y movilidad social. Un análisis a partir de familias granadinas del siglo XVIII”, en Gómez González, I. y LóPez-Guadalupe MuÑoz, M. L. (eds.): La movilidad social en la España del Antiguo Régimen, Granada, Comares, 2007, pp. 223-247; AndúJAR CASTILlo, F.: "Milicia y nobleza. Reformulación de una relación a partir del caso granadino (siglos XVII-XVIII)", en ANDÚJAR CASTILlO, F. Y Jiménez Estrella, A. (eds.): Los nervios de la guerra: estudios sociales sobre el ejército de la monarquía hispánica (siglos XVI-XVIII): nuevas perspectivas, Granada, Comares, 2007, pp. 251-276.

12 Giménez Carrillo, D. M.: "Los militares y las órdenes militares castellanas durante el reinado de Felipe V", en García Hurtado (ed.), op. cit. (nota 8), pp. 215-236.

13 Como es obvio, la inmensa mayoría, tuvieron la denominación de Títulos de Castilla (321), en tanto que los de Navarra (8) y Aragón (1) fueron prácticamente residuales. Para calcular los militares que fueron agraciados con dichos títulos nobiliarios hemos considerado a aquellos que tuvieron en la carrera de las armas su principal ocupación profesional, quedando por tanto excluidos los oficiales de milicias, fundamentalmente los más numerosos de "milicias de Indias", muchos de los cuales obtuvieron los títulos por servicios pecuniarios más que por méritos militares.

14 Archivo Histórico Nacional (AHN), Consejos (C), libros 626, 627, 628, 2752, 2753; Archivo General de Simancas (AGS), Dirección General del Tesoro (DGT), Inv. 24, leg. 702. 
Cuadro 1. Títulos nobiliarios concedidos a militares y grados en el momento de titular.

\begin{tabular}{|c|c|}
\hline Grado & Número de títulos nobilarios \\
\hline Capitán General & 1 \\
\hline Teniente General & 4 \\
\hline Mariscal de Campo & 2 \\
\hline Brigadier & 3 \\
\hline Coronel & 6 \\
\hline Teniente Coronel & 5 \\
\hline Capitán & 2 \\
\hline Total & 23 \\
\hline
\end{tabular}

Fuente: Elaboración propia a partir de AHN, C, libros 626, 627, 628, 2752, 2753; AGS, DGT, Inv. 24, leg. 702.

Comentar uno por uno los militares que obtuvieron títulos nobiliarios excedería los límites de esta aportación pero algunas lecturas e interpretaciones se pueden obtener del mencionado cuadro. Por ejemplo, es posible interrogarnos acerca de qué méritos diferenciadores de los demás intendentes tuvo el de Valencia en 1761, José Avilés Itúrbide, para ser encumbrado a marqués de Avilés cuando ostentaba el rango más bajo del generalato, el de brigadier? Una respuesta inmediata, y por otro lado, coherente con las dinámicas para la obtención de los títulos nobiliarios ${ }^{15}$, radicaría en que José Avilés, disponía de los recursos suficientes para pagar los derechos del título y, lo que era más importante, para portarlo, como se decía en la época con la "decencia y decoro y lustre" que se exigía a quienes iban a ostentar tales distinciones. ${ }^{16}$ Sin embargo, sabemos por un estudio de Ricardo Franch Benavent, que la pesquisa que sufrió en 1762 durante el ejercicio de su cargo de intendente de Valencia sacó a la luz numerosas irregularidades y prácticas corruptas que le permitieron alcanzar un notable enriquecimiento ilícito. ${ }^{17}$ Habría que pensar pues que los méritos del militar, devenido luego en intendente, respondieron más a la intervención de un posible "factor venal" en la obtención del título nobiliario que a sus servicios castrenses que, hasta esa fecha de 1761, en que consiguió ser marqués de Avilés, no habían pasado del umbral de brigadier, un rango de la jerarquía militar que se situaba a medio camino entre los de la oficialidad de los regimientos -el de coronel-y el primer nivel del generalato, el grado de mariscal de campo.

Tampoco podía acreditar grandes servicios José Antonio Bravo Sobremonte, ennoblecido como marqués de Sobremonte en marzo de 1761, el mismo año que Avilés. Por entonces, al igual que este último, ostentaba el rango de brigadier, y unos meses antes de recibir el título nobiliario había sido nombrado gobernador y capitán general de la provincia de Cartagena de Indias. Sus servicios hasta esa fecha podían esgrimirlos otros oficiales del mismo cuerpo - el de Guardias Españolas de Infantería- en el que había servido el nuevo marqués. Lo reflejado en el título, de estar en

Véase, Felices de la Fuente, M. M.: La nueva nobleza titulada de España y América en el siglo XVIII (17011746). Entre el mérito y la venalidad, Almería, Universidad de Almería, 2012.

16 Ibidem, p. 158.

17 Franch Benavent, R.: "Las oportunidades de enriquecimiento ilícito generadas por el ejercicio de la intendencia más 'tentadora' de España: la pesquisa realizada al marqués de Avilés como intendente de Valencia en 1762", Estudis. Revista de historia moderna, 28 (2002), pp. 263-286. 
posesión de 38 años de servicios, haber participado en las guerras de Italia, e incluso haberse distinguido en la conocida "sorpresa de Veletri" 18 , fue lo que se utilizó para adornar aquella concesión pero, sin duda, detrás de la misma debieron estar otras "poderosas razones" de mayor fuerza como para encumbrarse hasta la cima de la nobleza titulada.

Semejantes consideraciones pueden hacerse en torno al título de marqués de la Algorfa concedido en 1762 al oriolano Francisco Ruiz Dávalos. Su historial castrense no era excesivamente brillante y tampoco debió ser el mérito principal para alcanzar aquella distinción. Su carrera la había iniciado en noviembre de 1719 ingresando directamente en el ejército con el grado de capitán del regimiento de dragones de Cartagena al adquirir una patente de ese rango a José Caro Maza, levantador de dicha unidad. ${ }^{19}$ En el momento de titular como marqués llevaba más de 42 años de servicio en el ejército pero no debía ser su carrera de excesiva relevancia pues no había pasado del rango de coronel. Sin embargo debió contar con poderosos mediadores en su favor, quienes, desde luego, no sustentaron sus avales en razones de peso, y menos aún en méritos militares sino por el contrario en argumentos que, interpretados en su contexto, bien podrían considerarse como cercanos a lo grotesco. De ese modo se puede interpretar la carta que el marqués de Villadarias, inspector general de la caballería y dragones, envió en enero de 1762 al Secretario del Despacho de Guerra, Ricardo Wall. Lo avalaba Villadarias, informando favorablemente para que se le otorgara el título, comunicándole al ministro que Ruiz Dávalos es "de las familias más ilustres del reino de Murcia; y tiene rentas suficientes para mantenerse con el lucimiento y carácter que desea, pues llegarán a cinco mil pesos". ${ }^{20}$ La escasa cuantía de la cifra se comenta por sí sola como referente de unos argumentos que, sin lugar a dudas, venían a formar parte del ceremonial necesario para cumplir unos trámites administrativos que en ningún caso debieron ser los determinantes para que Ruiz Dávalos pudiera verse revestido con el título de marqués.

En suma, parece evidente que derramar la sangre en los campos de Marte o acreditar una brillante hoja de servicios no bastaban para subir todos los peldaños de la jerarquía social. Un ejemplo postrero lo avala con rotundidad. En 1778 el limeño Luis Fermín Carvajal Vargas, hijo del conde de Castillejo y del Puerto, futuro duque de San Carlos, obtuvo el título nobiliario de conde de la Unión cuando llevaba tan solo 12 años de servicios en el ejército, pues había ingresado como cadete del regimiento de Guardias Españolas de Infantería en enero de $1766^{21}$, y contaba con 26 años de edad. El joven conde, con tan exigua carrera, servía como segundo teniente del mencionado regimiento de Guardias. Unos meses antes de morir en combate en la campaña del Pirineo Oriental, y cuando ya ostentaba el rango de teniente general, fue nombrado capitán general de Cataluña, pero en el momento de lograr el título nobiliario ni tenía un grado militar alto ni había intervenido en acción bélica alguna. Lo significaba con rotundidad el coronel del regimiento en 1780, es decir, dos años después de que fuera intitulado ya como conde de la Unión. En el marco de un informe positivo señalaba lo siguiente: "Campaña, ninguna; valor, promete; aplicación, bas-

\footnotetext{
Archivo General de Indias (AGI), Indiferente General (IG), leg. 545, lib. 4.

19 No de otro modo se explica que en su hoja de servicios conste que su primer servicio en la milicia fue el de capitán, pues además su patente de dicho grado coincide con la fecha de formación del regimiento que levantó José Caro. AGS, Guerra Moderna (GM), leg. 2462, C. IV.

20 AGS, GM, leg. 1130.

21 AGS, GM, leg. 2586.
} 
tante; capacidad, bastante; conducta buena [...] este oficial está en aptitud de continuar su mérito, siendo a propósito, según lo que demuestra para granaderos, y para cualquier comisión, desempeñando su obligación con celo y aplicación". ${ }^{22}$ Se trataba pues de una valoración muy similar a la que podían acreditar cientos de oficiales del ejército borbónico, muchos de ellos con rango de generales e incluso curtidos en mil batallas. Entonces ¿por qué se le recompensó con el título de conde? La interrogante podría tener múltiples respuestas y, una vez más, a falta de méritos militares, es preciso recurrir a diferentes hipótesis. Desde luego, una primera pista nos podría conducir hasta una acaudalada familia criolla que era propietaria, entre otros, del oficio de Correo Mayor de Indias, un cargo que se reincorporó a la Corona en 1768 tras negociación entre el fiscal Campomanes y el padre del militar, el conde de Castillejo y del Puerto. ${ }^{23}$ De lo que tenemos poca duda es de que, carente de servicios militares, el que iba a ser conde de la Unión contó con fuertes apoyos en la Corte y en el seno de la propia institución militar. En 1778 el conde de O'Reilly lo consideró como acreedor a recibir cualquier gracia de Carlos III, tanto por su distinguida calidad como por "ser conveniente que la nobleza de América vea atendidos a los individuos beneméritos que vienen al exército de España" ${ }^{24}$ Valer de émulo para los jóvenes de la aristocracia criolla americana podía ser un buen argumento que compensara la carencia de servicios militares pero, a falta de estos, la obtención del título de conde de la Unión por parte Luis Fermín Carvajal debió estar apoyada por otras "razones" ajenas a su trayectoria y condición de militar.

Por tanto, a pesar de vivir en una sociedad estamental que tanto apreciaba a la cima de la jerarquía nobiliaria, representada por la nobleza titulada, el militar carecía de ese estímulo que suponía - al menos en teoría- que una brillante hoja de servicios en la carrera de las armas o una destacada acción militar, se viese recompensada con las altas distinciones que otorgaba el soberano en premio a esos servicios. La excepción más relevante que sí respondió a esa lógica fue el del francés Luis Bertón Crillón, remunerado en el año 1783 con el título de conde de Mahón por su protagonismo en la acción militar que permitió recuperar para España la isla de Menorca que estaba en poder de las tropas inglesas. ${ }^{25}$

En el mismo plano de casos excepcionales han de situarse los de unos pocos militares que lograron sus títulos nobiliarios cuando disfrutaban de la graduación más alta del escalafón, la de tenientes generales. Se trata de los militares de origen irlandés, Alejandro O'Reilly (conde en 1772) ${ }^{26}$ y Bernardo O'Connor Phaly (conde en 1776), del extremeño Vicente Ovando (marqués de Camarena la Real en 1776), y de Bernardo Gálvez que fue distinguido como conde en 1783 en paralelo a su nombramiento como virrey de Nueva España, es decir, con la finalidad de que sirviese "más condecorado" dicho cargo. ${ }^{27}$

La trayectoria militar de los dos generales irlandeses, reunía todos los requisitos para que el premio de la alta distinción nobiliaria recayese sobre unos servicios que, en el momento de recibir el título, eran incuestionables. O’Reilly, acababa de servir

\footnotetext{
Ibidem.

23 Vallejo García-Hevia, J. M.: "El Correo Mayor de las Indias (1514-1768)" en Barrios Pintado, F. (ed.): Derecho y administración pública en las Indias hispánicas: actas del XII congreso internacional de historia del derecho indiano, Cuenca, Ediciones de la Universidad de Castilla-La Mancha, 2002, tomo II, pp. 1785-1810.

24 AGS, GM, leg. 2907.

25 TerRón PONCE, J. L.: La reconquista de Menorca por el duque de Crillón (1781-1782): aspectos militares y politicos, Mahón, Museo Militar San Felipe, 1981.

26 Sobre O’Reilly véase Recio Morales, O.: "Una aproximación al modelo del oficial extranjero en el ejército borbónico: la etapa de formación del teniente general Alejandro O'Reilly (1723-1794)", Cuadernos Dieciochistas, 12 (2011), pp. 171-195.

27 AHN, C, leg. 5085.
} 
como comandante en jefe en la expedición para la reconquista de la Luisiana y desde junio de 1770 se había unificado en su persona toda la inspección de la infantería al ser destinado a la capitanía general de Aragón el otro inspector, Antonio Manso. ${ }^{28}$ Ese nombramiento venía acompañado de la importante misión de continuar en España la labor que iniciara años atrás en América y que no era otra que proceder al "restablecimiento de la disciplina y la subordinación en la infantería". Por su parte Bernardo O'Connor había sido honrado con el título de conde de Ofalia (evidente castellanización de su apellido irlandés de O'Phaly) en julio de 1776 cuando por entonces, amén de ostentar como O'Reilly el rango de teniente general de los reales ejércitos, había desempeñado cargos fundamentales en el organigrama político de la monarquía, como el de gobernador político-militar de Barcelona entre septiembre de 1761 y marzo de 1772, período durante el cual asumió en varias ocasiones de forma interina el puesto de Comandante General de Cataluña, hasta que en la última fecha citada pasó a la Comandancia General del Ejército y Principado de Cataluña. ${ }^{29}$ No obstante, dados sus continuos enfrentamientos con la Audiencia de Cataluña ${ }^{30}$, apenas duró unos meses al frente de aquella capitanía general pues sería nombrado en noviembre de 1772 para ejercer dicho cargo en la de Castilla la Vieja, y en febrero de 1774 pasó a servir la Capitanía General de la costa del Reino de Granada. ${ }^{31}$

Por último, anotar que lo analizado en relación a las recompensas, o en propiedad, a las "no recompensas", del mérito en la carrera de las armas se podría hacer extensible a las encomiendas de las Órdenes Militares. Un reciente estudio de Gijón Granados demuestra con claridad que el principal cambio que se produjo en la política de los Borbones en relación a las encomiendas, tuvo lugar a partir de la década de los años treinta cuando las que mayores rentas proporcionaban fueron patrimonializadas por los infantes de la Casa de Borbón, quedando por tanto los militares al margen de unas remuneraciones que, en teoría, por su origen, debían haber recaído en quienes derramaban su sangre en defensa del rey en los campos de guerra. ${ }^{32}$

En consecuencia, el incentivo que pudo haber supuesto en la carrera militar la obtención de los honores quedó reducido a los hábitos de las órdenes militares castellanas. Y es en ese marco en el que se entiende mejor la creación de la nueva orden militar, la de Carlos III, y sus cruces pensionadas que, para algunos militares supuso la posibilidad de obtener unos ingresos adicionales. Por tanto, esa medida, de crear una nueva orden militar con el nombre del monarca, en cierto modo vino a compensar la pérdida patrimonial que habían experimentado los militares desde que Felipe V iniciara la política de otorgar las principales encomiendas de las órdenes a los infantes.

28 AGS, GM, leg. 2581

29 Gay EscodA, J. M.: El corregidor a Catalunya, Madrid, Marcial Pons, 1997, p. 565.

30 Esos conflictos adquirieron tales dimensiones que en julio de 1770 solicitó a Carlos III que le confiriese una de las capitanías generales "que no tenga relación con las Audiencias, acomodando más a mi genio la última de esta especie que la mejor de las otras". AGS, GM, leg. 1458.

31 AGS, DGT, Inv. 2, legs. 56 y 58.

32 Gijón Granados, J. De Á.: El reformismo de las Órdenes Militares en la Ilustración (1700-1809). Las Reales Encomiendas de la Casa Borbón, El Ejido, Círculo Rojo, 2011. 


\section{La carrera en el generalato: recompensar la antigüedad}

Durante el reinado de Carlos III no se introdujo modificación alguna en el sistema de promoción en la carrera de las armas pues siguieron vigentes los mismos criterios que habían prevalecido desde comienzos de la centuria, salvo que ahora una menor actividad bélica comportó también un menor número de promociones u "hornadas". Los oficiales generales de Carlos III llegaron a esos puestos y progresaron en cada uno de los grados del generalato en razón de la antigüedad en el rango, no en función de criterios meritocráticos. ${ }^{33}$ Pervivió el sistema de promociones periódicas fundamentadas en los años de servicio, un método que venía a consagrar las profundas diferencias establecidas en los empleos inferiores del escalafón en donde la venalidad de los $\operatorname{cargos}^{34}$ por un lado y, por otro, los privilegios concedidos a los aristocráticos cuerpos de las Guardias Reales ${ }^{35}$, marcaron distancias abismales en las carreras de los oficiales del ejército borbónico. La posibilidad de ingresar directamente con el rango de capitán al adquirir un empleo con motivo de la formación de un nuevo regimiento - $\mathrm{u}$ ocasionalmente de comprarlo directamente en la Corte como sucedió al inicio de la década de los años cuarenta y luego entre 1766 y 1772- así como los excepcionales privilegios que disfrutaban los miembros del "ejército cortesano", en donde fue posible ingresar directamente como coronel al conseguir un puesto de exempto en las Guardias de Corps, fueron dos procesos paralelos que generaron tipologías de carreras muy desiguales en el seno del ejército borbónico. Por tanto, cuando a partir de 1760 se iniciaron las hornadas de oficiales generales, que tuvieron una cadencia de diez en diez años, el criterio que prevaleció fue el de la antigüedad en el escalafón, entendiendo por tal, no los años de servicio en el ejército sino la antigüedad en el rango que daba acceso al generalato, para unos autores el de coronel, para otros el de brigadier. Fuera de esas grandes hornadas decenales tan solo hubo promociones muy puntuales de algunos oficiales por motivos concretos, algunos de ellos por razones ajenas a lo que era la propia profesión militar.

La cronología es muy clara. Las hornadas tuvieron una secuencia decenal, a excepción de la de abril de 1763, hecha para premiar los servicios de la guerra contra Portugal. Por tanto, se hicieron en junio de 1760, abril de 1770 y junio de 1779 , de modo que, paradójicamente, la siguiente correspondió al momento del acceso de Carlos IV al trono pues fue hecha pública en enero de 1789. Por otro lado, la guerra, como mecanismo de promoción profesional, tuvo momentos puntuales, si bien no todos ellos fueron tan exitosos como para haber supuesto "hornadas remuneratorias". La excepción principal sería la mencionada guerra de Portugal de 1762, pero luego habría que contabilizar los frustrados intentos de recuperación de Gibraltar en los años de 1775 y 1779-1782, la también frustrada expedición a Argel de julio de $1775 \mathrm{y}$, finalmente, la reconquista de Menorca en 1782. En América las acciones bélicas más importantes fueron, amén de la pérdida de La Habana en 1762, la conquista

33 Andújar Castillo, F.: "Las elites de poder militar en la España borbónica. Introducción a su estudio prosopográfico", en Castellano, J. L. (ed.): Sociedad, Administración y Poder en la España del Antiguo Régimen, Granada, Universidad de Granada, 1996, pp. 207-235; ANDúJAR CASTILlo, F.: "La carrera militar en la España del siglo XVIII", en Dedieu, J.- P., Vincent, B. (eds.): L'Espagne, l'État, les Lumières. Mélanges en l'honneur de Didier Ozanam, Madrid, Bordeaux, Casa de Velázquez, 2004, pp. 189-214.

34 AndúJar Castillo, op. cit. (nota 3).

35 Andújar Castillo, F.: "Elites de poder militar: las Guardias Reales en el siglo XVIII", en Castellano, J. L., Dedieu, J.-P., López-Cordón, Mª . V. (eds.): La pluma, la mitra y la espada. Estudios de historia institucional en la Edad Moderna, Madrid, Marcial Pons, 2000, pp. 65-94. 
de la colonia de Sacramento en 1763, la expedición a América en el año 1780 y la toma de Pensácola en 1781.

El ejército que luchó en esas contiendas, a su vez, estuvo formado por tres grandes grupos de unidades y, por ende de militares, con notables diferencias entre cada uno de ellos: el grueso de la institución militar, formado por las armas de infantería y caballería -inclusa en esta el cuerpo de dragones-, que bien podríamos denominarlo como "ejército regular" para diferenciarlo de otro ejército, de menor número de hombres pero con mayores privilegios y distinciones respecto a aquél, conformado por los cuerpos que se encargaban de la vigilancia del rey, y que denominamos como "ejército cortesano" -formado por los dos grandes regimientos de Guardias de Infantería, Españolas y Walonas, las tres compañías de Guardias de Corps, la compañía de Alabarderos y la brigada de Carabineros Reales-, y finalmente las armas técnicas, artillería e ingenieros, que tuvieron un débil peso, cuantitativo y cualitativo, en el conjunto del ejército.

Sobre esa estructura cabe interrogarse sobre los criterios que se utilizaron para ascender en el seno del ejército de Carlos III en los empleos del generalato. La cuestión se podría plantear desde otra perspectiva, y que no es otra que preguntarnos si hasta el generalato llegaron los oficiales más cualificados, los que se habían formado mejor, quienes más se habían distinguido en acciones militares o quienes, en suma, acreditaban una hoja de servicios con un historial más brillante. La misma interrogante nos lleva a cuestionarnos acerca de si durante el reinado de Carlos III se introdujeron o no cambios en el ejército que hubieran permitido situar en la cúspide del mando militar a oficiales generales seleccionados de acuerdo con criterios meritocráticos. El lector avisado podrá interrogarse a su vez acerca de cómo, en una estructura política articulada en torno a criterios estamentales, podrían tener cabida principios burgueses, y más propios del liberalismo, como los que podían estar en derredor del mérito. Veamos los datos.

Si tomamos como referencia de la hornada general del año 1770 los militares que fueron promovidos a la máxima distinción de teniente general, los resultados son concluyentes: de los 22 oficiales que alcanzaron el rango de teniente general, 15 de ellos provenían de las tropas de la Casa Real, en tanto que 7 procedían de los regimientos del "ejército regular", fundamentalmente de infantería y caballería. La lectura de esos datos en modo comparativo es contundente. Si damos crédito a las cifras recogidas en el Estado Militar de $1769^{36}$-aunque en conjunto estimamos que están evaluadas al alza, o lo que es lo mismo, más contando las fuerzas teóricas que las existentes realmente- las Guardias Reales, que en aquel momento suponían el 10,3\% de los efectivos del ejército, aportaban el 68,1\% de los ascendidos a tenientes generales. Una segunda lectura resulta tan reveladora como la anterior: de los 22 nuevos tenientes generales, 13 de ellos estaban adornados con sendos títulos nobiliarios, en tanto que los 9 restantes eran extranjeros y segundones de Casas de esa nobleza titulada.

Si los datos anteriores los cruzamos con otros parámetros de análisis los resultados son aún más elocuentes. El cuadro 2 muestra las edades con que accedieron al grado de teniente general los oficiales promovidos en la hornada del año 1770. De los 13 hemos podido determinar la fecha exacta de nacimiento de 9 de ellos, entre los cuales, los cuatro que llegan a ese grado a una edad más temprana, bien merecen un comentario adicional.

36 Quatrefages, R.: “L'Armée de Charles III”, en Dedieu, Vincent (eds.), op. cit. (nota 33), p. 184. 
Cuadro 2. La nobleza titulada en la hornada de 1770. Edad de acceso al grado de teniente general.

\begin{tabular}{|l|c|}
\hline Nombre & Edad \\
\hline Vicente Ovando, marqués de Camarena & 70 \\
\hline Antonio López Zúñiga, conde de Miranda del Castañar & - \\
\hline Cayetano Pignatelli, marqués de Rubí & 40 \\
\hline Fernando Prado, marqués de Villel & 56 \\
\hline Procopio Bassecourt, marqués de Bassecourt & - \\
\hline Victor Amadeo Attendo, conde Bolognino & 58 \\
\hline José Gregorio Mauro, marqués de Vallesantoro & 45 \\
\hline Marino Besso Ferrero, conde de Lavagna & 48 \\
\hline Marcos Ibáñez Segovia, marqués de Mondejar & - \\
\hline Guillermo Baillencourt, conde de Renato & - \\
\hline Pedro Zoilo Téllez, duque de Osuna & 42 \\
\hline José Álvarez Bohorquez, marqués de Ruchena & 46 \\
\hline Francisco Antonio Tineo, marqués de Casatremañes & 57 \\
\hline
\end{tabular}

Del cuadro destacan, en primer término, las diferencias de edades en alcanzar ese máximo rango del escalafón militar. Contrasta la edad de 70 años que tenía el marqués de Camarena cuando fue promovido a teniente general con los 42 años del duque de Osuna o con los 40 que tenía el marqués de Rubí ¿Dónde estuvo el origen de esas diferencias? ¿Fueron militares más destacados aquellos que llegaron a la cima del generalato a una edad más temprana o incidieron en sus carreras otros factores? Como veremos, las respuestas a tales interrogantes no pueden ser uniformes, pero sí esclarecedoras de los factores que influían de forma decisiva en las trayectorias de los que iban a ocupar los máximos rangos del generalato.

Tomamos como referencia los cuatro tenientes generales más jóvenes de entre los que pertenecían a la nobleza titulada: el marqués de Rubí, el marqués de Vallesantoro, el duque de Osuna y el marqués de Ruchena. En el caso del primero lo decisivo no estuvo en su trayectoria como militar sino en la influencia del factor familiar sobre su cursus honorum. Cayetano Pginatelli, marqués de Rubí, nació en el seno de una familia de larga trayectoria castrense pues su abuelo, Domingo Pignatelli, marqués de San Vicente alcanzó igualmente el rango de teniente general y fue capitán general de Galicia, en tanto que su padre, Francisco Pignatelli, llegó a esa misma graduación y estuvo al frente de la Capitanía General de la costa de Granada y su reino entre mayo de 1746 y junio de 1749 , fecha esta última en la que fue nombrado embajador extraordinario de España en Francia. ${ }^{37}$ Pues bien, Cayetano Pignatelli, nacido en octubre de 1730, cuando tan solo contaba con 16 años de edad obtuvo una "gracia regia" por la cual, merced a los servicios de su padre, se le dio el rango de capitán del regimiento de dragones de la Reina. ${ }^{38}$ Corría el mes de abril de $1747 \mathrm{y}$, por tanto, su padre por entonces estaba al frente de la Capitanía General de Granada. Ese nombramiento le catapultó en el escalafón militar y se vio refrendado poco después cuando en el año 1749 cambió de arma y recibió dos nombramientos, primero

37 Ozanam, D.: Les diplomates espagnols du XVIIIe siècle, Madrid, Casa de Velázquez, 1998, pp. 396-397.
38 AGS, GM, leg. 1103. 
de teniente coronel y luego de coronel del regimiento de infantería de Nápoles ${ }^{39}$, cargo este último que no debió desempeñar pues acompañó a su padre en Francia cuando fue nombrado embajador. En todo caso, tuvo el nombramiento de coronel de un regimiento en junio de 1749 cuando aún no había cumplido los 19 años de edad.

La misma influencia del factor familiar es más que evidente en el caso de José Gregorio Mauro, marqués de Vallesantoro. Nacido en 1726, sirvió en regimiento napolitano de infantería de Parma hasta que llegó a España en 1760 de la mano de su padre, el marqués de Squilache, quien de inmediato se encargó de promocionarle. Primero, lo situó en el prestigioso regimiento de Guardias Españolas de Infantería, en la hornada de ese año de 1760 fue promovido a brigadier, y en 1763 a mariscal de campo, aprovechando la nueva promoción que se hizo tras la guerra de Portugal. El peso de la familia continuaría años después, ya que, como señaló Gay Escoda, en marzo de 1772 cuando ya ostentaba el grado de teniente general fue nombrado gobernador político-militar de Barcelona por los méritos de su padre, a pesar de que había otros tenientes generales con mayor antigüedad que la suya que pretendían ese mismo puesto. ${ }^{40}$

El VIII duque de Osuna, Pedro Zoilo Téllez Girón, tuvo una meteórica carrera sustentada en su alta alcurnia, desde luego, pero sobre todo en la patrimonialización de los cargos militares que la familia había conseguido, en concreto en el regimiento de Guardias Españolas de Infantería. ${ }^{41}$ Nacido en junio de 1728 en Madrid, con tan solo siete años de edad ingresó en el citado regimiento que había mandado su padre hasta su fallecimiento en marzo de 1733. Por tanto, titulado ya como duque de Osuna, su carrera en el seno de aquella unidad militar fue tan rápida como que en diciembre de 1749 fue ascendido a capitán de dicho regimiento, un grado que equivalía en los regimientos de infantería al de coronel de los reales ejércitos. Perteneciendo a tan ilustre Casa y de tan rancio abolengo, en 1763 pasó a mandar la compañía de Alabarderos y en marzo de 1770 el regimiento de Guardias Españolas de Infantería, el mismo que su padre mandara años atrás. Como no podía estar al frente de esa unidad con el rango de mariscal de campo, en la hornada del mes siguiente, abril de 1770, fue ascendido a teniente general. Dada su privilegiada posición en palacio y el lustre de su Casa, el rey ordenó de inmediato que se le pagase el sueldo de teniente general "empleado" - lo cual suponía la percepción del sueldo asignado cuando se estaba en la situación de "en cuartel"- y que además acumulara también el sueldo de Coronel de Guardias Españolas de Infantería. ${ }^{42}$

El cuarto teniente general perteneciente a la nobleza titulada más joven de aquella hornada fue José Alvarez Bohorquez, marqués de Ruchena. Su historial como militar estuvo solidamente apoyado en la influencia familiar en dos ámbitos convergentes, en palacio, en la cercanía de los monarcas, y en el poderoso cuerpo de las Guardias de Corps que se encargaban de la seguridad del rey en el interior de palacio. Su padre Antonio José Álvarez Bohorquez, marqués de Ruchena, sirvió en dicho cuerpo, primero en la compañía española y luego en la plana mayor de las tres compañías de Guardias de Corps. Su madre, Winfreda White, pertenecía a una influyente familia irlandesa que junto a su madre y tres hermanas se situaron en el epicentro del po-

\footnotetext{
AGS, GM, leg. 2626.

Gay Escoda, op. cit. (nota 29), p. 567.

AndúJar Castillo, F.: "La Corte y los militares en el siglo XVIII", Estudis, 27 (2001), p. 116.

AGS, GM, leg. 2316.
} 
der al comenzar a servir desde el año 1710 como camaristas de la reina ${ }^{43}$ Con tan poderosos avales José Álvarez Bohorquez, nacido en agosto de 1724, ingresó como exempto de la compañía española de Guardias de Corps, un puesto que equivalía en los regimientos del ejército regular al de coronel ${ }^{44}$ Era su primer servicio en la milicia y lo hacía directamente como coronel, pero no era algo nuevo en la familia pues su padre había accedido al ejército por la misma senda en 1702, directamente con el grado de capitán de caballería, para cuatro años más tarde ascender a coronel al obtener un puesto de exempto en la misma compañía que años después lo iba a hacer su hijo. ${ }^{45}$

Tomemos ahora como referencia el grupo de los que hemos denominado como segundones y extranjeros de la hornada de tenientes generales del año 1770 , para analizar el mismo parámetro de la edad en que alcanzaron ese grado en el ejército borbónico.

Cuadro 3. Segundones y extranjeros en la hornada de tenientes generales de 1770.

\begin{tabular}{|l|c|}
\hline \multicolumn{1}{|c|}{ Nombre } & Edad \\
\hline Miguel López Fernández & - \\
\hline $\begin{array}{l}\text { Antonio Ricardos Carrillo (nieto del duque de Montemar; padre Teniente General y } \\
\text { Capitán General de Venezuela) }\end{array}$ & 43 \\
\hline Cristóbal Zayas (nieto del marqués de las Torres, capitán general) & 59 \\
\hline Nicolás Bucarelli (será marqués de Vallehermoso por consorte en 1782) & 56 \\
\hline Melchor Bernarldo de Quirós & 66 \\
\hline Manuel Azlor Urríes (segundón del conde de la Guara) & 62 \\
\hline Francisco Tavares Barrios (segundón del marqués de Casa Tavares) & 64 \\
\hline José Lemire (flamenco) & 75 \\
\hline Jorge Dunant (suizo) & \\
\hline
\end{tabular}

Procedentes en su mayoría de los cuerpos de Guardias Reales (seis de los nueve ascendidos provenían de ellos) la edad media de acceso se encuentra cercana a los 60 años excepto Antonio Ricardos Carrillo, en cuyo caso, una vez más, el factor familiar se erige en determinante de una trayectoria profesional marcada por la precocidad inherente a los privilegios que otorgaba pertenecer a un linaje noble, militar, pero sobre todo con extraordinario poder en el seno del ejército. Su carrera bien merece ser comentada, aun de forma somera, con mayor detalle.

Nacido en Barbastro en septiembre de 1727, Antonio Ricardos era hijo de Felipe Nicolás Ricardos, que llegó a ser teniente general en 1751 y capitán general de Venezuela. Cuando cumplió los diez años de edad, tal vez como regalo de cumpleaños, sentó plaza de cadete de caballería, y al año siguiente fue ascendido a capitán. Si con 11 años era capitán, con 18 ocupaba el puesto de teniente coronel del regimiento de caballería de Malta y antes de cumplir los 20 ya mandaba ese regimiento ¿Qué méritos avalaban tan extraordinaria trayectoria? ¿Su experiencia y capacidad profesional? No parece que se pueda dar una respuesta positiva a tales interrogantes pues el

43 AndúJar Castillo, F.: "Familias irlandesas en el ejército y en la Corte borbónica", en García Hernán. E. y Recio Morales, O. (coords.): Extranjeros en el ejército. Militares irlandeses en la sociedad española, 1580-1818. Madrid, Ministerio de Defensa, 2007, p. 287.

44 Gaceta de Madrid, 1744-05-09.

45 AndúJar CASTillo, op. cit. (nota 43), p. 287. 
origen de tan fulgurante carrera no fue otro que su abuelo materno, el duque de Montemar, que ejerció como Ministro de Guerra entre marzo de 1737 y mayo de 1747 en que falleció, justo el período en que su nieto fue promovido en sucesivas ocasiones hasta situarlo al mando del regimiento de caballería de Malta. De hecho, su nombramiento como coronel del regimiento en el que había ascendido a teniente coronel en enero de 1746 se produjo en el mes de abril de 1747, un mes antes de que falleciese su poderoso abuelo. ${ }^{46}$ Luego vendrían sus sucesivas promociones a brigadier (1760), mariscal de campo (1763) y teniente general (1770) hasta culminar su carrera como capitán general de Cataluña desde enero de 1793, cargo que desempeñaría hasta su muerte en el mes de marzo del año siguiente. Pero incluso llegó a disfrutar del honroso título de capitán general de los reales ejércitos por haberse distinguido al mando de las tropas del Rosellón y, especialmente, en la batalla de Masdeu. ${ }^{47}$

\section{La hornada de tenientes generales de 1779: venalidad y nobleza versus ciencia}

Si avanzamos en el tiempo y analizamos la hornada de tenientes generales que se hizo en junio de 1779, la última del reinado de Carlos III, constatamos que todo se mantuvo con las mismas pautas que las descritas hasta aquí. Los cuerpos de las Guardias Reales coparon la mayoría de los puestos de aquella promoción, pues de un total de 27 mariscales de campo promovidos a tenientes generales, 13 de ellos procedían de esas unidades. Del mismo modo, por lo que hace al origen social, 14 poseían títulos nobiliarios, en tanto que los restantes eran en su gran mayoría segundones de Casas tituladas. ${ }^{48}$ Pervivían pues las mismas características de un generalato en el que la impronta aristocrática y la pertenencia a los cuerpos que servían en la proximidad del monarca actuaban como factores decisivos en la promoción en la carrera de las armas.

Sin embargo, al igual que sucediera en la hornada de 1770 , en la de 1779 se pone de manifiesto de nuevo cómo, además de la incidencia del factor familiar -léase aristocrático, que sumado a la pertenencia a una saga militar añadía más factores para una mejor proyección profesional-y de la decisiva pertenencia a los cuerpos que servían en la cercanía del monarca, los elementos claves de las carreras de los que iban a ser futuros oficiales generales no estuvieron precisamente en los rangos del generalato sino en los empleos de la oficialidad, en donde la incidencia de ambos factores fue determinante para que las trayectorias de unos u otros militares fueran divergentes. A todo ello habría que sumar la influencia que tuvieron los procesos venales en el ejército borbónico, o lo que es lo mismo, a la posibilidad de adquirir los empleos del escalafón con ocasión de la formación de nuevos regimientos o en las coyunturas en que se vendieron directamente en la Corte. Dos carreras, de sendos

\footnotetext{
AGS, GM, leg. 2472, C. X.

Gaceta de Madrid, 23 de julio de 1793.

48 Los tenientes generales de aquella hornada fueron: Francisco Lacy, conde de Lacy; Joaquín Ibáñez Cuevas, marqués de Cañada Ibáñez; Mariano Éboli, duque de Castropignano; Juan Vicente Guemes, conde de Revillagigedo; Martín Álvarez de Sotomayor, conde de Colomera; Felipe Fonsdeviela Ondeano, marqués de Torre; Antonio Benavides Cueva, duque de Santisteban; Francisco Madariaga Cea, marqués de Villafuerte; Bernardo Grimaldo, marqués de Grimaldo; Pedro Chassebreuil, marqués de Roche; Toribio Cruz Gasca, marqués de Revilla; Eugenio Alvarado, marqués de Tabalosos; Álvaro Navia Osorio, Vizconde de la Herrería; Onofre Córdoba Ramírez de Haro, conde de Bornos, AGS, DGT, Inv. 2, leg. 63.
} 
tenientes generales de la hornada de 1779 , ejemplifican la decisiva incidencia de la venalidad.

El primero de ellos, Domingo Joaquín Salcedo Castellanos, comenzó sus servicios en el ejército en marzo de 1746 cuando tenía 18 años de edad, y lo hizo directamente como coronel. Que su entrada en la milicia fuese el de coronel se explica porque "benefició" -compró- ese grado por un servicio de recluta de 300 hombres, que en realidad no acabó reclutándolos sino que satisfizo en dinero al abonar 105.000 reales en que estaba calculada la leva de soldados. ${ }^{49}$ Evidentemente con esa "experiencia" no se le confirió el mando de ningún regimiento sino que fue agregado al de infantería de Navarra, pero años después, siendo su "antigüedad" en el grado de coronel desde aquel año de 1746 se vio favorecido por las promociones de 1763 (brigadier), 1770 (mariscal de campo) y 1779 (teniente general), para culminar su carrera como capitán general de las costas y ejército de Andalucía en 1786, tras haber sido durante largos años gobernador de Ceuta (1770-1784). ${ }^{50}$ Detrás de esa carrera, en el momento de conseguir un puesto de coronel sin haber visto jamás un arma, estuvo la riqueza acumulada por su padre en América, quien tras haber servido como capitán general de Yucatán entre 1734 y 1745, tuvo caudales para invertir en su hijo y en sí mismo, pues en junio de 1745 adquirió una plaza de consejero de Indias merced al desembolso de 9.000 pesos, es decir, 135.000 reales. $^{51}$

El segundo caso es similar al anterior, si bien presenta un matiz diferenciador por cuanto no alcanzó el grado de teniente general en 1779 sino tres años antes, por lo tanto "fuera de hornada". La razón a ese anticipado ascenso estuvo en que se había distinguido en la expedición a Argel del año 1775, a pesar de que ésta resultara un fracaso para las tropas de Carlos III. No obstante, su trayectoria anterior estuvo jalonada por "méritos pecuniarios". Hijo de un comerciante de Vitoria, Bartolomé José Ortiz de Urbina, al igual que se hermano Juan Manuel, vio notablemente impulsada su carrera por la riqueza familia. Nacido en 1721, ingresó en la Academia de Guardias Marinas en septiembre de $1737^{52}$, sin embargo pronto debió abandonar la Armada para servir en el ejército pues ingresó directamente con el grado de capitán en el regimiento de infantería de Cantabria. En febrero de 1746 se procuró un nuevo ascenso a teniente coronel, esta vez por haber ofrecido un servicio de recluta de 150 hombres a razón de 20 pesos cada soldado, que finalmente no reclutó sino que pagó en dinero efectivo, sumando por tanto la adquisición del puesto 45.000 reales. $.^{53} \mathrm{Mu}-$ chos años después su cursus honorum se vería culminado con la obtención del rango de "capitán general de los ejércitos" en 1792, poco antes de ser nombrado capitán general de Valencia y Presidente de su Audiencia. ${ }^{54}$

Para concluir y analizar con mayor precisión los criterios que prevalecían en la promoción de los generales del ejército borbónico nos interrogamos acerca de la importancia que se concedió a las armas técnicas en el reinado de Carlos III. Se ha insistido en el incuestionable avance que supuso la creación de la Academia de Ar-

ANDÚJAR CASTILlo, op. cit. (nota 3), p. 199.

AGS, DGT, Inv. 2, leg. 70.

AGS, DGT, Inv. 15, Guión 19, leg. 8.

VÁlgoma y Díaz-VARela, D. DE la: Real Compañia de Guardiasmarinas y colegio naval. Catálogo de pruebas de Caballeros aspirantes, Madrid, Consejo Superior de Investigaciones Científicas, 1943, tomo I, p. 657.

AGS, GM, leg. 5055.

54 AGS, DGT, Inv. 2, leg. 79 e Inv. 24, leg. 264. 
tillería de Segovia ${ }^{55}$, y en los frutos que dio, claramente manifestados en figuras tan insignes como la de Tomás Morla. ${ }^{56}$ Pero cabría cuestionarse si, en una coyuntura en la que esas armas de artillería e ingenieros cobraban un mayor protagonismo en la mayoría de los ejércitos europeos, tuvieron en España la misma proyección y si esa relevancia que debieron tener se tradujo en una posición más destacada en los estratos del generalato español.

Aunque los datos que hemos ido avanzando en esta investigación apuntan hacia un cuerpo de oficiales generales nucleado en torno a principios sociales, aristocráti$\cos$, y en derredor de los privilegios que otorgaba servir en la proximidad del soberano, un estudio comparativo de dos trayectorias, la de un ilustre e ilustrado ingeniero, Pedro de Lucuce, y la de un noble napolitano, Mariano Eboli, duque de Castropignano, ponen de manifiesto diferencias abismales que reflejan cómo, al margen de la mencionada política de creación de centros de formación para la educación de los militares, en la práctica, el mérito de los conocimientos científicos y técnicos quedó relegado en favor de los servicios cortesanos, de la cercanía al monarca, de la sangre ilustre y, en suma, del favor que las relaciones sociales anudaban en los principales espacios de decisión política.

Amén de su condición de militares, el único elemento de unión entre ambos lo podemos hallar en que fueron promovidos a tenientes generales en la misma hornada, la del mes de junio de 1779. Al noble napolitano ya le dedicamos algunos renglones en una aportación anterior ${ }^{57}$ a los que ahora, para establecer el estudio comparativo con Pedro de Lucuce, añadimos nuevos registros, precisamente para ponderar en su justa medida el valor otorgado en la política militar de Carlos III al estudio, a la ciencia y a la formación científica.

Mariano Eboli Revertera, hijo del duque de Castropignano, quien fuera también teniente general en 1734 y capitán general de los ejércitos de Nápoles, nació en Nápoles el 7 de junio de 1742. Su padre se apresuró a sentarle plaza en aquel ejército y cuando aún no había cumplido los tres meses de edad ya gozaba del puesto de cadete del regimiento napolitano de Guardias Italianas de Infantería. El "bebé militar" prosiguió su exitosa trayectoria y justo al cumplir los cinco años de edad ya era teniente del mismo regimiento. Dos años después, en enero de 1749 fue ascendido a capitán, y el patrocinio familiar prosiguió en los años siguientes, de modo que, ostentando su padre el rango de capitán general del ejército de Nápoles, subió otro peldaño más al obtener el grado de coronel de infantería. Así pues, era un niño de 12 años que ya vestía los galones de coronel. ${ }^{58}$ Después de suceder a su padre en el título de duque de Castropignano tras la muerte de este en febrero de 1758, pasó a España con Carlos III, quien en junio de 1760 lo nombró coronel del regimiento de infantería de África y un mes después lo premió aún más al concederle el grado de brigadier. Por tanto, recién cumplidos los 18 años ya se había situado a las puertas del generalato. Tras participar en la campaña de Portugal en 1762 fue ascendido a mariscal de campo en $1770 \mathrm{y}$ a teniente general en la promoción de 1779. En consecuencia, debió ser un buen regalo de aniversario aquel

55 Herrero Fernández-Quesada, Ma . D.: La enseñanza militar ilustrada: el Real Colegio de Artillería de Segovia, Segovia, Academia de Artillería, 1990.

56 Herrero Fernández-QuesadA, Ma . D.: Ciencia y milicia en el siglo XVIII: Tomás de Morla, artillero ilustrado, Segovia, Patronato del Alcázar, 1990.

57 AndúJar CAStillo, F.: "Entre la Corte y la guerra. Militares italianos al servicio de España en el siglo XVIII", Guerra e Pace in etá Moderna. Annali di Storia militare europea, 1 (2008), pp. 133-134.

58 AGS, GM, leg. 2508. 
ascenso pues el 9 de junio cumplió 37 años y la hornada de tenientes generales se publicó al día siguiente. Los avatares de su disoluta vida, los numerosos escándalos que protagonizó por deudas, e incluso la privación de sus bienes que sufrió por parte del Consejo de Guerra en 1775, no detuvieron su carrera militar, antes al contrario continuó imparable hasta lo más alto del escalafón. Con su habitual solvencia Davide Maffi ha documentado de forma muy precisa todos los problemas económicos que Mariano Eboli tuvo como consecuencia de los gastos generados por su alegre vida en la Corte. ${ }^{59}$ Retengamos pues la edad y el grado: teniente general a los 37 años.

En el otro extremo tomamos ahora como elemento de comparación el caso de un ingeniero militar y matemático, Pedro de Lucuce, sobradamente conocido en la historiografía española por la inmensa labor que desarrolló en diversos campos relacionados con su profesión así como por la publicación, entre otras obras, de los Principios de fortificación, que vieron la luz en 1772. Numerosos autores se han ocupado de su biografía y obra como ingeniero y no vamos a insistir sobre lo ya conocido. ${ }^{60}$ Tan solo anotar de forma sumaria que nació en noviembre de 1692 en Avilés, y que tras cursar estudios de Filosofía y Teología ingresó en las Guardias de Corps, cuerpo que abandonó para ingresar en el de ingenieros, en donde gozó del rango de ingeniero extraordinario desde febrero de 1733, pasando en 1738 a ejercer como profesor de la Academia de Matemáticas de Barcelona, de la cual sería director desde el año siguiente hasta el de su muerte en noviembre de $1779 .{ }^{61}$ Desde 1774 también ostentaría el cargo de director de las Academias de Matemáticas de Orán y Ceuta. Probablemente esa lejanía de la Corte debió influir para que fuera relegado en la hornada de oficiales generales de 1760, tanto como que fue ascendido a brigadier fuera de hornada en enero de 1762 pero concediéndole la antigüedad de la promoción de 1760. Diez años después ascendió a mariscal de campo, y en 1779 a teniente general. Por tanto había llegado a ese alto grado de la jerarquía militar a los 87 años de edad.

La comparación entre ambas biografías es, ante todo, una invitación a la reflexión cuando insistimos en el concepto de reformismo militar en tiempos de Carlos III. Identificar el impulso a la creación de Academias o la promulgación de las Ordenanzas de 1768 con la idea de reforma, según el argumentario que venimos desarrollando, es cuando menos cuestionable, máxime si, como hemos mostrado en las últimas líneas de esta aportación, constatamos que dirigir la Sociedad de Matemáticas de Barcelona o ser un destacado técnico no sirvieron a Pedro de Lucuce para ver reconocidos sus méritos en el escalafón de oficiales generales del ejército borbónico. Encaja perfectamente en el contexto de la época que el duque de Castropignano pudiese alcanzar el generalato a una precoz edad, pues igualmente precoces habían sido sus ascensos, tanto como para ser un recién nacido y vestir ya galones. Nada anormal en el marco de la lógica del patronazgo familiar. Sin embargo, que el reconocimiento con la máxima distinción del generalato a Pedro de Lucuce le llegara cinco meses antes de su muerte, y a los 87 años de edad, no concuerda con quienes pretenden presentar el reformismo militar de Carlos III como paradigma de la Ilustración.

59 MAFFI, D.: "Ufficiali e gentiluomini. Aristrocratici italiani nell'esercito dei Borbone de Spgana (c.a. 1750-c.a. 1800)", Revista Storica Italiana, CXXVII-1 (2015), pp. 208-209.

60 En el marco de una extensa publicística sobre Lucuce, véase: CAPEL, H. y otros: Los ingenieros militares en España. Siglo XVIII. Repertorio biográfico e inventario de su labor científica y espacial. Barcelona, Edicions de la Universitat de Barcelona, 1983, pp. 274-277; Galland-SEguela, M.: Les ingénieurs militaires espagnols de 1710 à 1803: étude prosopographique et sociale d'un corps d'élite, Madrid, Casa de Velázquez, 2008.

${ }_{61}$ CAPEL y otros: op. cit. (nota 60), p. 274. 